\title{
Electrochemical biosensors for monitoring malolactic fermentation in red wine using two strains of Oenococcus oeni
}

\author{
M. Esti ${ }^{\mathrm{a}, *}$, G. Volpe $^{\mathrm{b}}$, L. Micheli $^{\mathrm{b}}$, E. Delibato $^{\mathrm{c}}$, \\ D. Compagnone ${ }^{d}$, D. Moscone ${ }^{b}$, G. Palleschi ${ }^{b}$ \\ a Dipartimento di Scienze e Tecnologie Agroalimentari, Università della Tuscia, via S. Camillo de Lellis, 01100 Viterbo, Italy \\ ${ }^{\mathrm{b}}$ Dipartimento di Scienze e Tecnologie Chimiche, Università Tor Vergata, Via della Ricerca Scientifica 1, 00133 Rome, Italy \\ ${ }^{\mathrm{c}}$ Lab. Alimenti, Istituto Superiore di Sanità, V.le. Regina Elena 299, 00161 Rome, Italy \\ d Dipartimento di Scienze degli Alimenti, Università di Teramo, via Spagna 1, Mosciano, 64123 Teramo, Italy
}

Received 29 July 2003; received in revised form 20 November 2003; accepted 3 December 2003

Available online 3 February 2004

\begin{abstract}
Amperometric biosensors for the determination of L-malic and L-lactic acids were optimised and used to monitor micro-malolactic fermentations (micro-MLFs) in red wine. Platinum-based probes, coupled with appropriate enzymes, were assembled in electrochemical flow-injection analysis systems. A classical lactate oxidase based sensor was used for L-lactic acid, while L-malic acid was detected via a new biosensor based on the malic enzyme immobilised in a reactor using phenazine methosulphate as mediator. After a preliminary optimisation phase, a recovery study to evaluate the effect of the matrix (red wine) on biosensor performance was carried out by the addition of different standard solutions of the two analytes to the samples. Recoveries from 93 to $100 \%$ and from 94 to $102 \%$ were observed for L-malic acid and L-lactic acid, respectively. These optimised biosensors were finally employed to monitor micro-MLFs induced by inoculation of two different strains of Oenococcus oeni into red wine. During the micro-MLFs, samples of wine were collected and assayed for L-malic, L-lactic, and citric acids by use of both biosensors and spectrophotometric techniques. In parallel the viable bacterial cell count was also evaluated. The kinetics of bacterial growth, degradation of L-malic and citric acids, and production of L-lactic acid was found to be a function of the strains inoculated. (C) 2003 Elsevier B.V. All rights reserved.
\end{abstract}

Keywords: Electrochemical biosensors; Malolactic fermentation; L-Malic acid; L-Lactic acid; Citric acid; Oenococcus oeni

\section{Introduction}

For the production of red wines, and some white wines, low levels of malic acid are considered a prerequisite for their commercialisation. Traditionally, the way to reduce the quantities of this acid has been to allow the spontaneous growth of lactic acid bacteria (naturally present in wine), which in turn carry out the malolactic fermentation (MLF). This process consists in the conversion of L-malic into L-lactic acid and $\mathrm{CO}_{2}[1,2]$. In addition to the deacidification, the MLF is considered to contribute to the complexity of the flavour and to confer a degree of microbiological stability to the wine $[3,4]$. Citric acid degradation, which also occurs during this fermentation, participates in the microbiological stabilisation by eliminating another source of energy.

\footnotetext{
* Corresponding author. Tel.: +39-076-1357498.

E-mail address: esti@unitus.it (M. Esti).
}

However, this metabolic process produces more than one molecule of acetic acid from each substrate molecule, plus other products, depending on the bacterial strain and growth conditions [5]. An important issue is that the spontaneous MLF most commonly occurs after completion of alcoholic fermentation when the wine conditions are favourable for the growth of lactic acid bacteria [6]. Several studies have shown that Leuconostoc oenos, recently reclassified as Oenococcus oeni [7], is adapted to high ethanol concentrations and low $\mathrm{pH}$ values in wine and is the organism responsible for MLF [8]. However, the spontaneous MLF is unpredictable and may occur only after long delays. This loss of time can be costly to wine producers. The delay also increases the possibility that spoilage bacteria may carry out MLF and, at the same time, produce off-odours and flavours [6].

In recent years, starter culture technologies involving the inoculation of $O$. oeni into wine have been developed for managing the MLF $[9,10]$. However, failures usually occur because of the lack of adaptation of the cultures to wine or 
because of cellular damage during storage of the commercial malolactic bacteria. Since the loss of viability is very high when the cells are directly inoculated into wine, starter cultures need one or more steps of reactivation and adaptation to wine before use in order to enhance the viability of the bacteria [10-12].

Thus, it is desirable to supply winemakers with new analytical systems that are simple, rapid and of low cost, to monitor the MLF and to establish the best strategy for its management.

Biosensor technology appears to be suitable for this purpose [13]. Several biosensors for the determination of L-malic and L-lactic acids have been reported [14-20].

The aim of the present study is the development of two flow injection analysis (FIA) biosensor systems and their application to the monitoring of MLF. These bio-systems are based on the electrochemical detection of $\mathrm{H}_{2} \mathrm{O}_{2}$ produced through the reactions catalysed by malic enzyme (coupled with an appropriate mediator) and lactate oxidase enzyme.

Micro-MLFs, induced by inoculation into red wine of two different strains of $O$. oeni, were carried out in our laboratory. The progress of the micro-MLFs was monitored by following the kinetics of bacterial growth, the degradation of L-malic and citric acids, and the production of L-lactic acid.

\section{Experimental}

\subsection{Reagents and materials}

Malic enzyme, lactate oxidase, $\mathrm{NADP}^{+}$, phenazine methosulfate, aminopropyl glass beads (average pore size $700 \AA, 80-120$ mesh) and all other reagents used for biosensors were purchased from Sigma (St. Louis, MO).

Polycarbonate membrane of $0.2 \mu \mathrm{m}$ pore size was from nucleopore (Pleasanton, CA); nylon net membrane (mesh: $120 \mathrm{~cm}^{-2}$, thickness: $100 \mu \mathrm{m}$ ) from A. Bozzone, Appiano Gentile, Italy. Cellulose acetate membrane with $100 \mathrm{Da}$ molecular weight cut off (MWCO) was prepared as previously reported [21]. For casting the cellulose acetate membrane, a precision gauge tool (from Precision Gauge and Tool Co., Dayton, OH) was used. The PTFE connection tubes $(0.5 \mathrm{~mm}$ i.d.) were from Supelco (Bellofonte, CA); the T-connector was from Omnifit (Boonton, NJ).

Spectrophotometric kits for L-malic, L-lactic and citric acids were from R-Biopharm GmBh (Roche) (Darmstadt, Germany). All reagents and materials used to monitor bacterial growth were purchased from Oxoid Ltd., Basingstoke, UK.

\subsection{Apparatus}

An amperometric biosensor detector (ABD), a hydrogen peroxide probe (which consists in a working platinum electrode combined with an $\mathrm{Ag} / \mathrm{AgCl}$ reference electrode), and a flow-through cell from Universal Sensors (USA) were used for amperometric measurements. The current output was recorded with an L 250 E $x-t$ recorder (Linseis, Selb, German). To perform FIA, a peristaltic pump, Minipuls 3, from Gilson (Gosport, France) and a model 5020 PTFE injection valve from Rheodyne (Rohnert Park, CA,) equipped with one of two loops $(100$ or $250 \mu l)$, were used.

\subsection{Analytical procedures}

\subsubsection{Assay reaction schemes}

The biosensor for the determination of L-malic acid is based on the reaction catalysed by malic enzyme (ME):

L-malate $+\mathrm{NADP} \stackrel{\mathrm{ME}}{\rightarrow}$ pyruvate $+\mathrm{NADPH}+\mathrm{CO}_{2}+\mathrm{H}^{+}$

NADPH in the presence of an appropriate mediator such as phenazine methosulfate (PMS) in the oxidised form, is able to reduce molecular oxygen forming $\mathrm{H}_{2} \mathrm{O}_{2}$. The reactions involved are as follows [22,23]:

$$
\begin{aligned}
& \mathrm{NADPH}+\mathrm{H}^{+}+\mathrm{PMS} \rightarrow \mathrm{NADP}^{+}+\mathrm{PMSH} \\
& \mathrm{PMSH}+\mathrm{O}_{2} \rightarrow \mathrm{PMS}+\mathrm{H}_{2} \mathrm{O}_{2}
\end{aligned}
$$

The biosensor for the determination of L-lactic acid is based on the reaction catalysed by lactate oxidase (LOX):

$$
\text { L-lactate }+\mathrm{O}_{2}+\mathrm{H}_{2} \mathrm{O} \stackrel{\text { LOX }}{\longrightarrow} \text { pyruvate }+\mathrm{H}_{2} \mathrm{O}_{2}
$$

For both biosensors the $\mathrm{H}_{2} \mathrm{O}_{2}$ produced was oxidised at the surface of the Pt electrode polarised at $+650 \mathrm{mV}$ versus $\mathrm{Ag} / \mathrm{AgCl}$.

\subsubsection{Enzyme immobilisation}

The LOX enzyme immobilisation procedure was carried out as reported in the literature [24]: $1 \mathrm{~cm}^{2}$ of nylon-net membrane was immersed in methylene chloride for $10 \mathrm{~min}$ and then placed (5 $\mathrm{min}$ at room temperature) in a $0.1 \mathrm{M}$ triethyloxonium-tetrafluoroborate (TOTFB) solution prepared in $\mathrm{CH}_{2} \mathrm{Cl}_{2}$. The membrane was washed three times with freshly prepared iced methanol and immersed in an aqueous solution of polyethylene imine (PEI 5\%, (w/v)) for $3.5 \mathrm{~h}$ at room temperature. After a three-cycle washing step in distilled water (DW), the nylon-net membrane with immobilised PEI was allowed to react with glutaraldehyde ( $1 \%(\mathrm{v} / \mathrm{v})$ in $0.1 \mathrm{~mol} \mathrm{l}^{-1}$ carbonate buffer, $\left.\mathrm{pH} 10\right)$ for $40 \mathrm{~min}$. After several washing steps in DW the membrane was incubated overnight at $4{ }^{\circ} \mathrm{C}$ with $2 \mathrm{mg} \mathrm{ml}^{-1}$ of LOX solution prepared in $0.1 \mathrm{moll}^{-1}$ phosphate buffer (PB) $\mathrm{pH} 6.85$ and finally washed with $0.5 \mathrm{moll}^{-1}$ glycine for $30 \mathrm{~min}$. When not in use the membrane was stored in $0.1 \mathrm{moll}^{-1} \mathrm{~PB}, \mathrm{pH}$ 7.0, containing Kathon $(0.1 \%(\mathrm{v} / \mathrm{v}))$ as antibacterial agent.

Malic enzyme is available only as a suspension in $2.9 \mathrm{M}$ ammonium sulfate, which could interfere with the immobilisation procedure. It was therefore dialysed using micro DispoDialyser ${ }^{\circledR}$ from Spectra/Por Membrane (MWCO: 
$25 \mathrm{kDa}$, volume $100 \mu \mathrm{l}$ ) as follows: $300 \mu \mathrm{l}$ of malic enzyme solution was dispensed into three dialysers which were then placed in 11 of $10 \mathrm{mM} \mathrm{PB}, \mathrm{pH} 7.0+0.5 \mathrm{mM}$ 2-mercaptoethanol $+3 \mathrm{mM}$ EDTA. The buffer was renewed three times at intervals of $4 \mathrm{~h}$. The dialysis was carried out at $4{ }^{\circ} \mathrm{C}$ with continuous stirring. After dialysis ME immobilisation was achieved by immersing $50 \mathrm{mg}$ of aminopropyl glass beads in glutaraldehyde $(2.5 \%(\mathrm{v} / \mathrm{v})$ in $10 \mathrm{mM} \mathrm{PB}, \mathrm{pH}$ 7.0) for $1 \mathrm{~h}$ with continuous gentle magnetic stirring. The beads were then extensively washed with DW and incubated overnight at $4{ }^{\circ} \mathrm{C}$ with $\cong 700 \mu l$ of the dialysed enzyme solution. The enzyme reactor was constructed by packing the beads into a $3 \mathrm{~mm}$ internal diameter Tygon tube. To retain the beads in the tube, a nylon disk ( 80 mesh) was glued at one end, the glass beads were loaded using the peristaltic pump and a second nylon disk was glued at the opposite end. The reactor, filled with working buffer, was stored at $4{ }^{\circ} \mathrm{C}$ when not in use.

\subsubsection{Biosensor assembly}

The biosensor for L-lactic acid was assembled by placing three membranes on an inverted electrode jacket in the following order: cellulose acetate membrane; enzymatic membrane; and a polycarbonate membrane which protects the enzyme from large molecules or bacteria. To assemble the sensor for L-malic acid, only cellulose acetate and polycarbonate membranes were used. In both cases the membranes were secured with an O-ring. The electrode jacket was filled with $0.1 \mathrm{moll}^{-1}$ potassium chloride (supporting electrolyte), the electrode was inserted into the jacket and screwed down until the tip of the platinum was firmly in contact with the membranes. Both the assembled biosensor and hydrogen peroxide sensor were inserted into a flow-through cell connected with a peristaltic pump. For the injection of the standard solutions or wine samples, an automatic valve, equipped with an appropriate loop, was inserted between the peristaltic pump and the electrochemical cell.

\subsubsection{Micro- $M L F$}

The optimised bio-systems were employed to monitor the micro-MLFs performed in our laboratory using wine obtained from "Montepulciano" grapes and produced at the Di Majo-Norante winery (Molise region). The principal analytical parameters of the wine are reported in Table 1. The fermentation process was carried out by inoculating wine, after pasteurisation, with two selected commercial strains of O. oeni: Lalvin 31 and Uvaferm alfa (Lallemand, Toulouse, France).

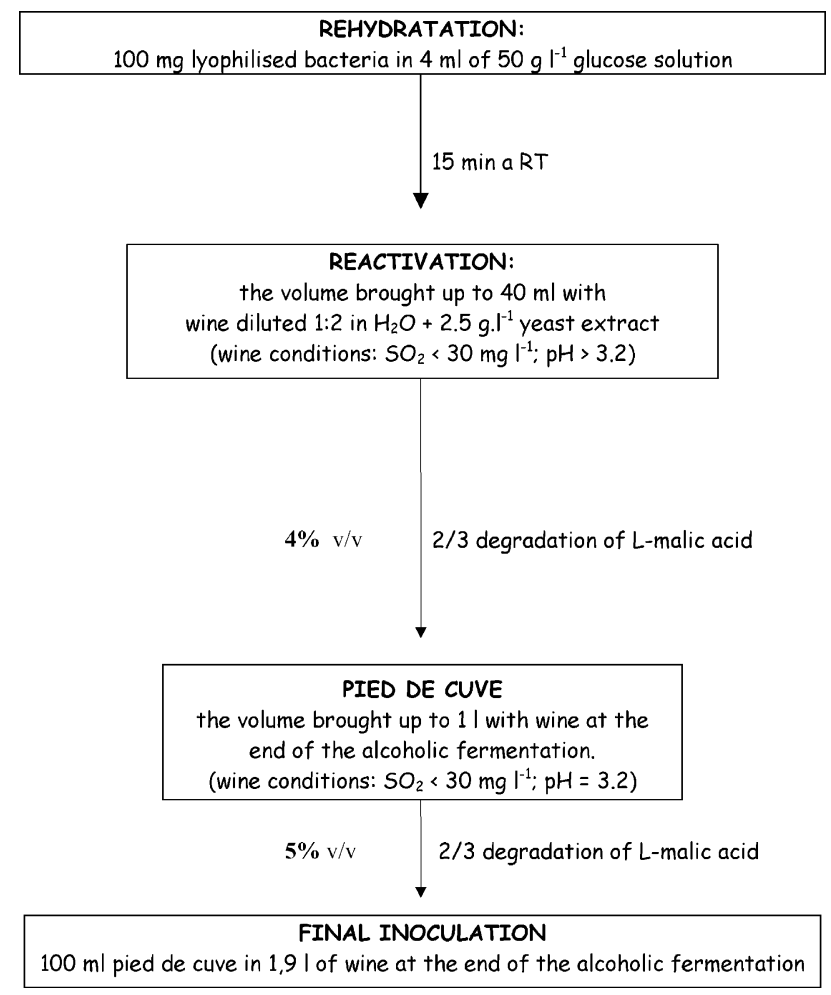

Fig. 1. Procedure used for bacterial reactivation.

In order to standardise the beginning of the metabolic process and to allow easier analytical and microbiological control, the starter cultures were inoculated into four wine batches after a reactivation procedure performed in wine [11]. The procedure used for the bacterial reactivation was the following: after rehydration of the lyophilised bacteria $(200 \mathrm{mg})$ in $4 \mathrm{ml}$ of a glucose solution $\left(50 \mathrm{~g} \mathrm{l}^{-1}\right)$, the suspension was added to $40 \mathrm{ml}$ of wine (diluted 1:2 in sterilised water) supplemented with an activator for lactic bacteria (yeast extract $2.5 \mathrm{~g} \mathrm{l}^{-1}$ ). When two-third of the L-malic acid was degraded, the suspension was again transferred into wine $(4 \%(\mathrm{v} / \mathrm{v}))$. After degradation of two-third of the L-malic acid, the reactivation medium ("pied de cuve") was finally inoculated into wine $(5 \%(\mathrm{v} / \mathrm{v}))$ to begin the MLF trial. The fermentations were carried out in fritted-capped glass flasks equipped with a tap. The scheme used for the reactivation procedure is summarised in Fig. 1.

In order to evaluate the effects of citric acid content on the malolactic reaction, two batches, one with a citric acid content of $250 \mathrm{mgl}^{-1}$ (endogenous concentration) and another one with a citric acid content of $500 \mathrm{mgl}^{-1}(\mathrm{ad}-$ dition of $250 \mathrm{mg} \mathrm{l}^{-1}$ ), were prepared for each strain of $O$.

Table 1

Main analytical parameters of the wine

\begin{tabular}{lllll}
\hline L-Malic acid $\left(\mathrm{g} \mathrm{l}^{-1}\right)$ & L-Lactic acid $\left(\mathrm{g}^{-1}\right)$ & $\mathrm{pH}$ & Titratable acidity (tartaric acid $\left.\mathrm{gl}^{-1}\right)$ & Alcohol $\left(\mathrm{vol}^{-1}\right)$ \\
\hline 3.4 & $<0.1$ & 3.3 & 5.9 & 14.1
\end{tabular}

Free $\mathrm{SO}_{2}$ and total $\mathrm{SO}_{2}$ were not detectable. 
oeni. Accordingly, Uvaferm alfa batches were designated as U250 and U500; Lalvin 31 batches, L250 and L500. Each batch was run in duplicate.

During the reactivation procedure and the micro-MLF trials, $2 \mathrm{ml}$ samples of wine (after having mixed the mass with a magnetic stirrer) were collected each day, and subsequently, anaerobic conditions were re-established by infusion of nitrogen for $1 \mathrm{~min}$. Samples collected prior to the final inoculation were analysed only for L-malic acid to assess its degradation to two-third of the initial content. By contrast, samples collected during the micro-MLF trials were assayed for:

- L-malic and L-lactic acids using both biosensor and spectrophotometric techniques;

- L-citric acid by a spectrophotometric kit;

- viable bacterial counts using the serial dilution method and seeding for inclusion in agar plates of MLO (medium for $L$. oenos). The latter is reported to be the best medium for easy and rapid growth of $O$. oeni [25]. The plates were incubated at $28^{\circ} \mathrm{C}$ into anaerobic jars (Oxoid) for 6-7 days before counting the colonies.

The MLO medium was prepared as following: $10 \mathrm{~g}$ of casein peptone tryptic digest (tryptone), $5 \mathrm{~g}$ of yeast extract, $10 \mathrm{~g}$ of glucose, $5 \mathrm{~g}$ of fructose, $0.2 \mathrm{~g}$ of $\mathrm{MgSO}_{4} \cdot 7 \mathrm{H}_{2} \mathrm{O}$, $0.05 \mathrm{~g}$ of $\mathrm{MnSO}_{4} \cdot \mathrm{H}_{2} \mathrm{O}, 3.5 \mathrm{~g}$ of diammonium citrate, $1 \mathrm{ml}$ of Tween $80,0.5 \mathrm{~g}$ of cysteine $\mathrm{HCl}, 10 \mathrm{~g}$ of $\mathrm{L}$-malic acid, $20 \mathrm{~g}$ of agar, dissolved in $900 \mathrm{ml}$ of distilled water. After adjustment of the $\mathrm{pH}$ to 5.5 , the medium was sterilised at $120^{\circ} \mathrm{C}$ for $20 \mathrm{~min}$. Then $100 \mathrm{ml}$ of sterilised tomato juice was added.

\section{Results and discussion}

\subsection{Configuration of the systems}

The analysis system assembled for L-lactic acid is shown in Fig. 2. An appropriate working buffer, $0.1 \mathrm{M}$ phosphate buffer, $\mathrm{pH}$ 7.0, was passed through the electrochemical cell by a peristaltic pump until a constant baseline current was reached. Then standard solutions or diluted wine samples were injected into the flow stream via the automatic valve loop and a transient current variation was recorded.

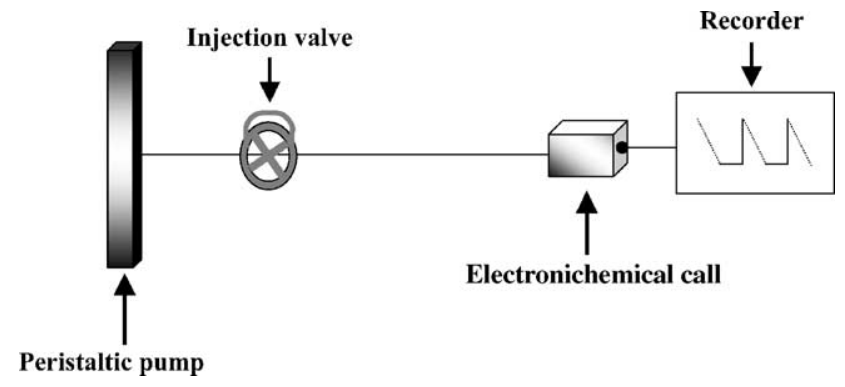

Fig. 2. Scheme of the FIA bio-system for L-lactic acid.
In the case of malic acid, the ME reactor was inserted between the automatic valve and the electrochemical cell (Fig. 3). An appropriate buffer, 0.05 M MOPS pH 7.4, was passed through channel ' $a$ ' of the peristaltic pump, while the same buffer containing PMS was passed through channel ' $b$ '. When a constant baseline current was reached, standard solutions or wine samples (diluted at least 1:100 in the working buffer) with added $\mathrm{NADP}^{+}$were injected into the flow stream. NADPH produced by the reaction catalysed by ME then merged in the mixing coil with the PMS carrier stream. After the reaction between NADPH and PMS, as for the scheme reported in Section 2.3.1, the $\mathrm{H}_{2} \mathrm{O}_{2}$ produced was oxidised at the Pt electrode surface and a transient current variation recorded.

For lactic acid, the wine samples had to be diluted at least 1:200 in the working buffer in order to eliminate electrochemical interference coming from electroactive species (with low molecular weight) present in wine. On the other hand, for malic acid analysis, a dilution of 1:100 was used initially since in this system the sample becomes diluted again by mixing with the carrier buffer. Thus the final dilution was comparable for both analyses.

\subsection{Optimisation of biosensor parameters}

In a preliminary phase, all analytical parameters of the biosensors were optimised. Different enzyme immobilisation procedures and supports were tested on electrode surfaces and the final methods chosen to best maintain enzymatic activity. For the determination of $\mathrm{L}$-malic acid a two-channel FIA manifold (Fig. 3) had to be adopted, with the introduction of an enzyme reactor, because an inhibitory effect of PMS on malic enzyme activity had been observed.

Various storage conditions were tested in order to attain a longer biosensor lifetime. For L-malic acid the response of the probe decreased by about $10 \%$ after 150 sample injections, whereas for L-lactic acid the response decreased by $35 \%$. Other parameters such as flow rate, loop volume, working buffer, PMS and $\mathrm{NADP}^{+}$concentrations (only for ME biosensor) were optimised. Operative and analytical performances of the resulting biosensors are reported in Table 2 .

\subsection{Evaluation of matrix effect}

Recovery studies to evaluate the effect of the matrix (red wine) on biosensor performance were carried out by spiking wine samples, before MLF (to test the recovery of the L-lactic acid) and after MLF (to test the recovery of the L-malic acid), with known amounts of the two analytes. Recovery (average of four measurements) and precision (R.S.D.\%) are reported in Table 3. Since samples must be diluted at least 1:100 for L-malic acid and 1:200 for L-lactic acid, these were the dilutions tested for recovery. The fortified levels were chosen so that they did not exceed the maximum limit of linearity of the biosensor devices in the optimised form. Further dilutions of the samples were 


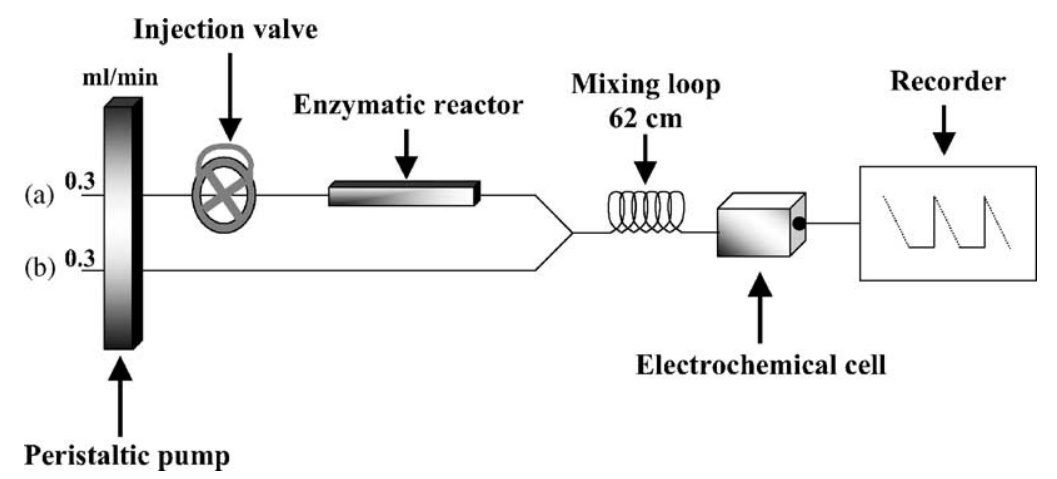

Fig. 3. Scheme of the FIA bio-system for L-malic acid.

Table 2

Operative and analytical performance of biosensor systems

\begin{tabular}{lll}
\hline & L-malic acid & L-lactic acid \\
\hline Enzyme used & Malic enzyme & Lactate oxidase \\
Working buffer & MOPS $0.05 \mathrm{moll}^{-1}, \mathrm{pH} 7.4$ & Phosphate $0.1 \mathrm{moll}^{-1}, \mathrm{pH} 7.0$ \\
Support for enzyme immobilisation & Aminopropyl glass beads packed into Tygon tube & Preactivated nylon net membrane \\
Applied potential $(\mathrm{mV}$ vs. Ag/AgCl) & +650 & +650 \\
Flow rate $\left(\mu 1 \mathrm{~min}^{-1}\right)$ & 300 for each channel & 500 \\
Loop volume $(\mu \mathrm{l})$ & 250 & 100 \\
Phenazine methosulfate & $1 \mathrm{mmol}^{-1}$ & - \\
NADP $^{+}$ & $1 \mathrm{mmol}^{-1}$ & - \\
Detection limit $\left(\mathrm{moll}^{-1}\right)$ & $3 \times 10^{-6}$ & $2 \times 10^{-6}$ \\
Linear range $\left(\mathrm{mol} 1^{-1}\right)$ & $10^{-5}$ to $4 \times 10^{-4}$ & $5 \times 10^{-6}$ to $10^{-3}$ \\
Response time $(\mathrm{min})$ & 3.5 & 3.0 \\
\hline
\end{tabular}

performed for higher analyte concentrations. A recovery between 93 and $100 \%$ and from 94 to $102 \%$ was observed for malic and lactic acids respectively, with a R.S.D. $<4 \%$ in all cases.

\subsection{Application of the biosensors to the malolactic fermentation}

Once satisfactory recovery and precision had been obtained, the biosensors were than used to monitor the micro-MLFs induced by inoculation of two different strains of $O$. oeni into wine samples. The evolution of L-malic, L-lactic and citric acid levels was followed as well as bacterial growth. The results are reported in Figs. 4 and 5 which show all the parameters monitored for the malolactic fermentation induced by the Uvaferm alfa and Lalvin 31 strains, respectively. The bacterial growth curves were markedly different for the two strains selected. In the case of Uvaferm alfa, an exponential growth phase (first to fourth day) was followed by a stationary phase. The Lalvin 31 strain, on the other hand, showed a short (1 day) exponential phase following 2 days of "lag" phase; slower growth was then observed up to day 5 , followed by a mortality phase.

The activation procedure (Fig. 1), performed for the adaptation of the starter cultures to the wine medium, was found to be suitable for all the inoculums employed and reduced the lag phase to at most 2 days. In all the trials, the malic acid degradation began when the viable cell concentration

Table 3

Recovery study performed by adding standard solutions of L-malic and L-lactic acids to red wine

\begin{tabular}{|c|c|c|c|c|c|c|}
\hline Analyte & Fortified levels & Before spiking & Expected values & Measured values & Mean $^{\mathrm{a}}$ recovery $(\%)$ & R.S.D. ${ }^{\mathrm{a}}(\%)$ \\
\hline \multirow[t]{4}{*}{ L-Malic acid $\left(\mathrm{g}^{-1}\right)$} & 1.4 & & 1.4 & 1.3 & 93 & 3.9 \\
\hline & 7.0 & 0.0 & 7.0 & 6.6 & 94 & 3.6 \\
\hline & 14.0 & & 14.0 & 13.4 & 96 & 3.2 \\
\hline & 56.0 & & 56.0 & 56.0 & 100 & 2.6 \\
\hline \multirow[t]{4}{*}{ L-Lactic acid $\left(\mathrm{g}^{-1}\right)$} & 0.2 & & 0.50 & 0.47 & 94 & 3.9 \\
\hline & 1.0 & 0.3 & 1.30 & 1.25 & 96 & 3.7 \\
\hline & 2.0 & & 2.30 & 2.30 & 100 & 3.5 \\
\hline & 10.0 & & 10.3 & 10.5 & 102 & 2.8 \\
\hline
\end{tabular}

After fortification, all samples were diluted 1:100 for L-malic and 1:200 for L-lactic acid and injected in the FIA biosystems.

a Relative standard deviation, four replicates. 

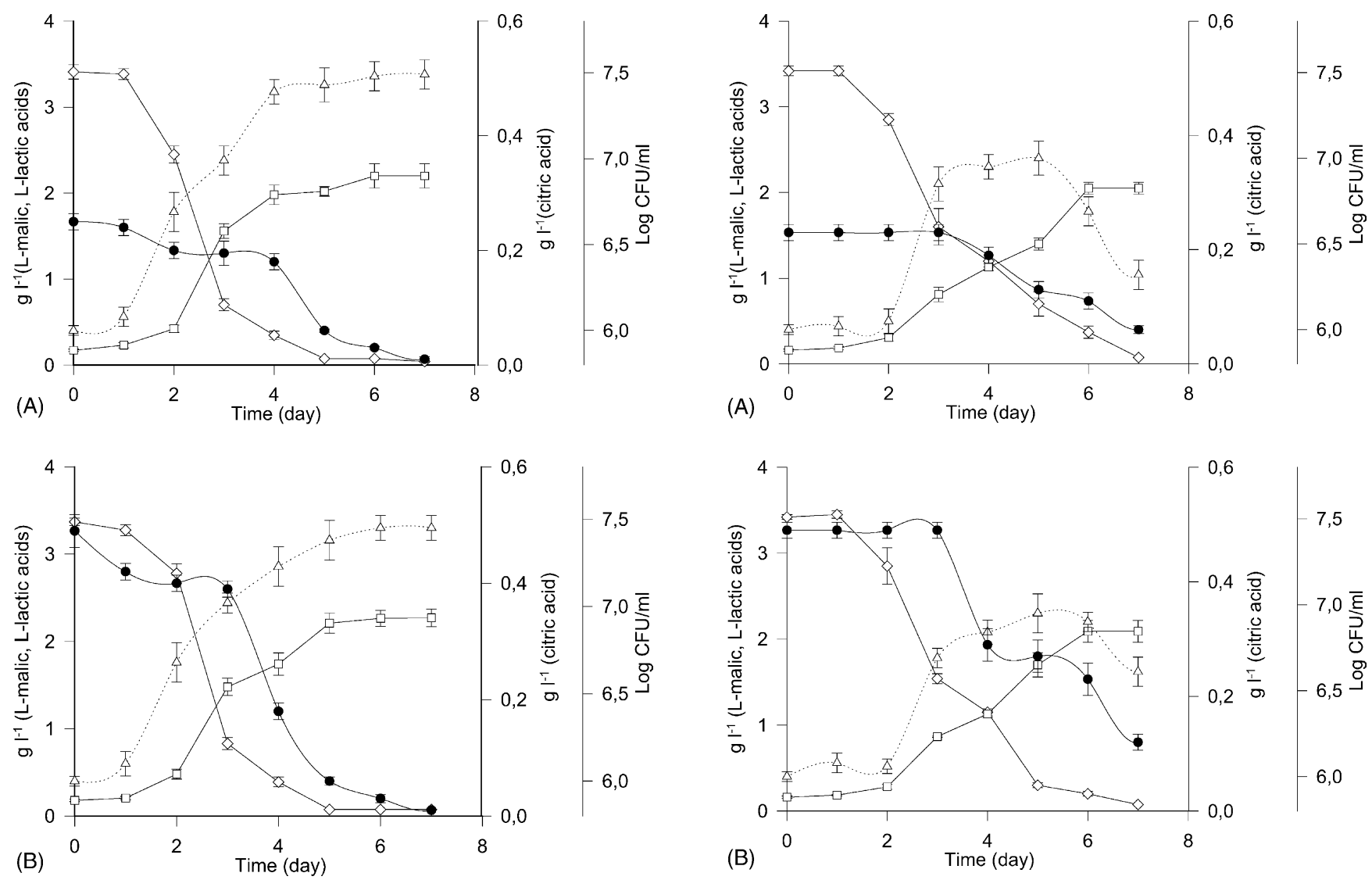

Fig. 4. Monitoring of the micro-MLFs using Uvaferm alfa as starter, $(\diamond)$ L-malic acid, $(\square)$ L-lactic acid, $(\bigcirc)$ citric acid, $(\triangle)$ bacterial count; (A) batch with an initial concentration of citric acid $=250 \mathrm{mgl}^{-1}$; (B) batch with an initial concentration of citric acid $=500 \mathrm{mgl}^{-1}$.

was $10^{6} \mathrm{CFU} \mathrm{ml}^{-1}$, as has been reported in literature [26], and the kinetics reached a maximum during the exponential cell growth phase for both strains. The different bacterial growth profiles exhibited by the two strains in turn determined the course of the degradation and production of L-malic and L-lactic acid respectively. In the trial with Uvaferm alfa strain, malic acid was consumed in 5 days, while it took 7 days for the Lalvin 31 strain.

During all the fermentations, the concentration of lactic acid in wine was lower than the level expected for complete conversion of malic acid (theoretical value of the ratio lactic $\mathrm{acid} / \mathrm{malic}$ acid $=0.67$ ). The ratio gradually approximated to the theoretical value during the MLF trials, reaching it only at the end of the process. This seems to indicate that lactic acid produced inside the bacterial cells is only gradually being released into the wine.

\subsection{Effects of citric acid levels}

The initial level of citric acid did not significantly influence either bacterial growth or the kinetics of the malolactic reaction. However, a higher rate of citric acid degradation resulted in the batches U500 and L500, which were char-

Fig. 5. Monitoring of the micro-MLFs using Lalvin 31 as starter, $(\diamond)$ L-malic acid, $(\square)$ L-lactic acid, $(\bigcirc)$ citric acid, $(\triangle)$ bacterial count; (A) batch with an initial concentration of citric acid $=250 \mathrm{mg}^{-1}$; (B) batch with an initial concentration of citric acid $=500 \mathrm{mgl}^{-1}$.

acterised by containing the maximum concentration of this acid normally found in wine.

It can be noted (Fig. 6) that the Uvaferm alfa strain already starts to metabolise citric acid during the first day and consumes it totally, independently of the initial concentration. On the other hand, the Lalvin 31 strain started to degrade citric acid only at day 3. Moreover when $90 \%$ of the malic acid was already degraded, $50 \%$ of citric acid was still present in the medium (Fig. 7). If confirmed, this behaviour of the Lalvin 31 strain could be of interest for winemaking technology. In fact, a close monitoring of malic and citric acid levels would allow that, once a consistent malic acid degradation is reached, the metabolic activity could be interrupted in such a way as to control to the amount of citric acid degradation products in wine.

\subsection{Biosensor validation}

Spectrophotometric tests for L-malic and L-lactic acids were performed in parallel with biosensor measurements in order to validate the use of these devices for monitoring the malolactic fermentation in wine. The results from 21 wine 


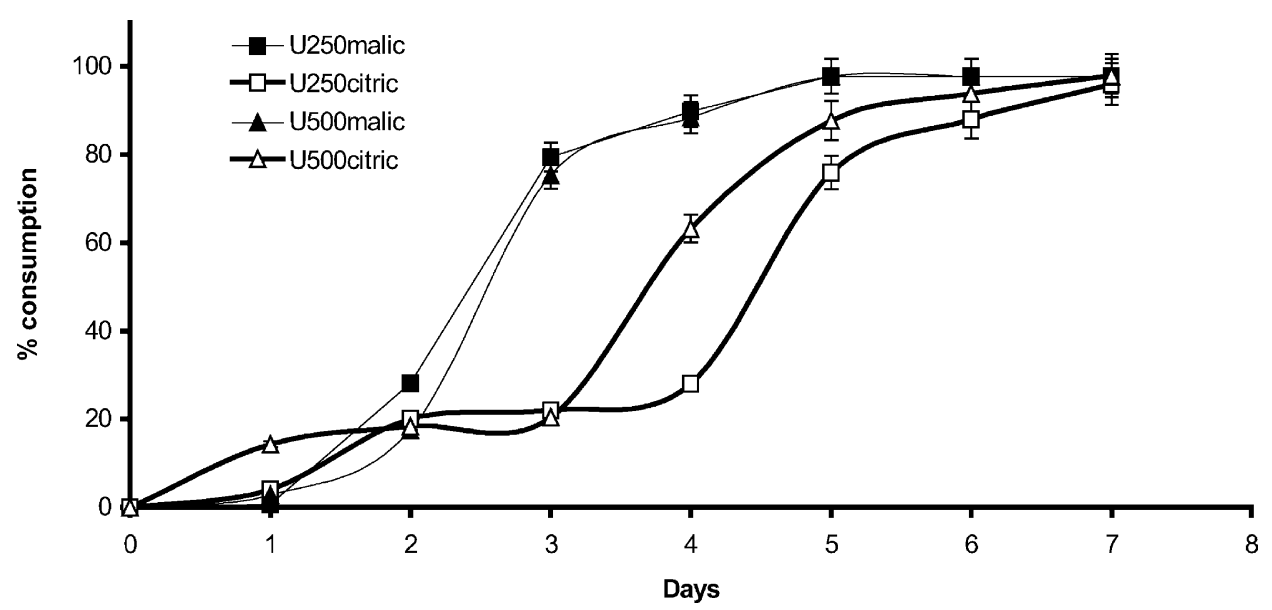

Fig. 6. Malic and citric acids (\% of consumption) during malolactic fermentation using Uvaferm alfa as starter.

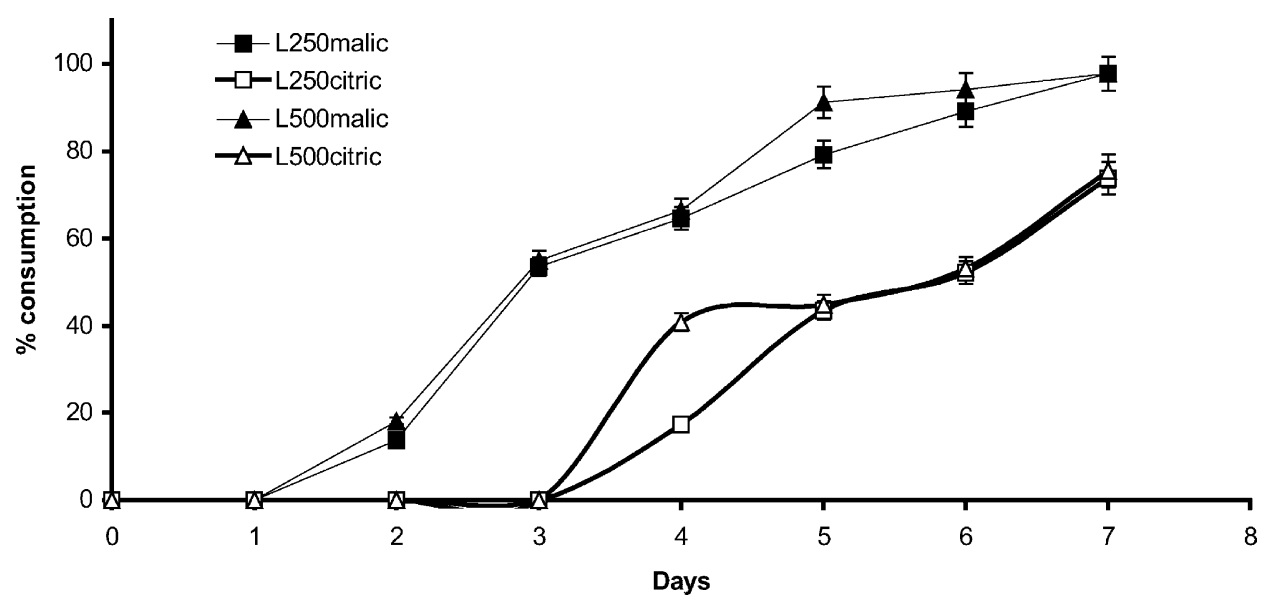

Fig. 7. Malic and citric acids (percentge of consumption) during malolactic fermentation using Lalvin 31 as starter.
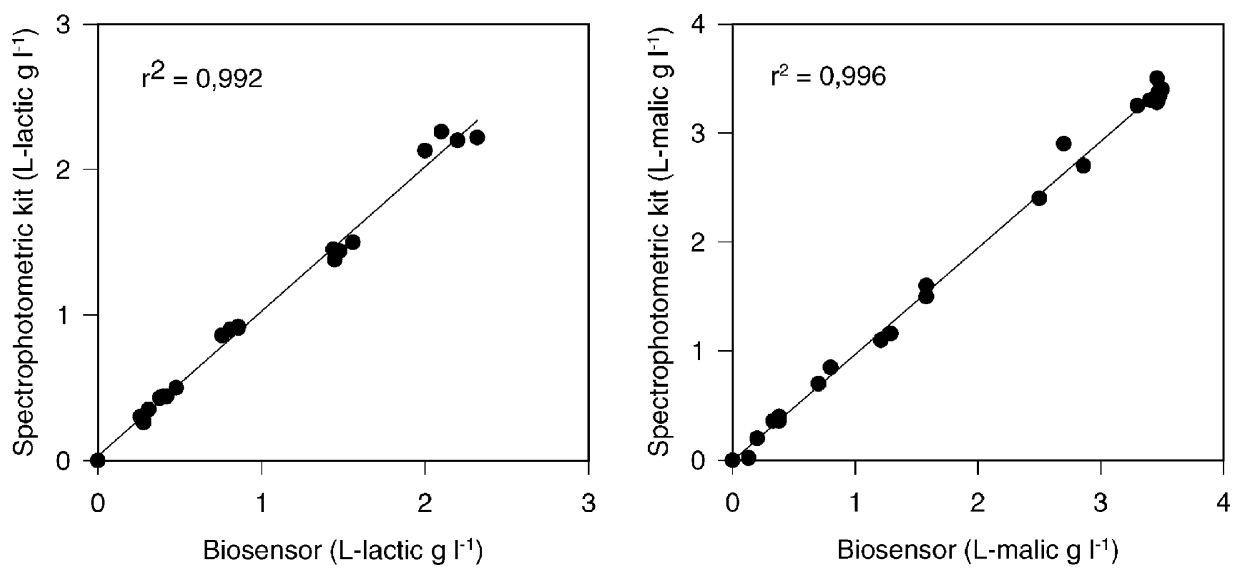

Fig. 8. Correlation between analyte (L-malic and L-lactic acid) values measured by spectrophotometric kits and bio-systems during micro-MLFs in red wine.

samples are reported in Fig. 8, demonstrating correlations $\left(r^{2}\right)$ of 0.996 and 0.992 for L-malic and L-lactic acids, respectively. These results demonstrate that an approach using biosensors holds great promise for real time on site monitoring in the winemaking industry.

\section{Conclusions}

Amperometric biosensors for the determination of L-malic and L-lactic acids were developed and applied in monitoring micro-MLFs induced using two different strains of $O$. 
oeni. The experimental data for the biosensors were in good agreement with spectrophotometric analysis demonstrating that the bioanalytical devices are suitable for following and managing this fermentation process.

In all trials the rate of malic acid degradation reached a maximum during the exponential cell growth phase. The rate of bacterial growth, and thus the degradation and production of L-malic and L-lactic acid respectively, were dependent on the strains inoculated. With the more reactive Uvaferm alfa strain, the malic acid degradation was completed in 5 days relative to the 7 days required with the Lalvin 31 strain.

\section{Acknowledgements}

The authors acknowledge the CNR target project on "Biotechnology", the CEE UE project cT 2002-00186 "NOVTECH", and CEE UEQLK1-cT 2002-70884 "CRAFT" for financial support. Lallemand-Italia is also acknowledged for bacterial strain supplied.

\section{References}

[1] R.E. Kunkee, Adv. Appl. Microbiol. 79 (1967) 235.

[2] D. Wibowo, R. Eschenbruch, C.R. Davis, T.H. Lee, Am. J. Enol. Vitic. 36 (1985) 302.

[3] C. Gao, G.H. Fleet, J. Appl. Bacteriol. 76 (1994) 632.

[4] T. Henick-Kling, J. Appl. Bacteriol. 79 (Suppl.) (1995) 29 S.

[5] P. Ribéreau-Gayon, D. Dobourdieu, B. Donèche, A. Lonvaud, Metabolism of Lactic Bacteria. Handbook of Enology, vol. 1, Wiley, West Sussex, UK, Chapter 5, p. 129.

[6] T. Henick-Kling, T.E. Acree, Modification of wine flavor by malolactic fermentation. Part 1: in: Proceedings of International Sympo- sium on the Management of Malolactic Fermentation and Quality of Wine, Vinitaly, Verona, Italy, 16 April 1998, Lallemand S.A., Toulouse Cedex France, 1998, p. 17.

[7] L.M.T. Dicks, F. Dellaglio, M.D. Collins, Int. J. Syst. Bacteriol. 45 (1995) 395.

[8] C.R. Davis, D. Wibowo, R. Eschenbruch, T.H. Lee, G.H. Fleet, Am. J. Enol. Vitic. 35 (1985) 290.

[9] C.G. Edwards, K.A. Jensen, S.E. Spayd, B.J. Seymour, Am. J. Enol. Vitic. 42 (1991) 219.

[10] J.C. Nielsen, C. Prahl, A. Lonvaud-Funel, Am. J. Enol. Vitic. 47 (1996) 42.

[11] A. Gandini, C. Tortia, D. Rossellini, Riv. Vitic. Enol. 4 (1995) 17.

[12] A. Cavazza, G.L. Vavassori, G. Volontario, Riv. Vitic. Enol. 2 (1999) 41.

[13] R.P. Buck, Sensor Issue for the 1990s: An introduction to the North Carolina Section American Chemical Society Symposium on Biosensors (Biosensor Technology), Dekker, New York, 1990, p. 3.

[14] A.M. Almuaibed, A. Townshend, Anal. Chim. Acta 221 (1989) 337.

[15] F. Mizutani, S. Yabuki, M. Asai, Anal. Chim. Acta 245 (1991) 145.

[16] S. Yoshioka, H. Ukeda, K. Matsumoto, Y. Osajima, Electroanalysis 4 (1992) 545.

[17] M.C. Messia, D. Compagnone, M. Esti, G. Palleschi, Anal. Chem. 68 (1996) 360.

[18] M.I. Prodromidis, S.M. Tzouwarakarayanni, M.I. Karayannis, P. Vadgama, A. Maines, Analyst 121 (1996) 435.

[19] N. Gajovic, A. Warsinke, T. Huang, T. Schulmeister, F.W. Scheller, Anal. Chem. 71 (1999) 4657.

[20] G. Palleschi, G. Volpe, D. Compagnone, E. La Notte, M. Esti, Talanta 6 (1994) 917.

[21] M. Mascini, F. Mazzei, Anal. Chim. Acta 192 (1987) 9.

[22] A.M. Almuaibed, Anal. Chim. Acta 428 (2001) 1.

[23] M. Vreeke, R. Maidan, A. Heller, Anal. Chem. 64 (1992) 3084.

[24] R.Q. Thompson, C.S. Mandoke, J.P. Womack, Anal. Lett. 18 (1985) 93.

[25] G. Caspritz, F. Radler, J. Biol. Chem. 258 (1983) 4907.

[26] M. Vincenzini, L. Granchi, S. Guerrini, R. Materassi, Ind. Bev. 30 (2001) 18. 